\title{
The Teaching Mode Research and Practice of the Engineering Personnel Innovation Ability Training Based on Virtual Instrument Experiment
}

\author{
S.Y. CHEN ${ }^{a}$, C.S. LIU, Y.C. JIANG \& T.L. WEI* \\ College of Mechanical Engineering, Jiamusi University, Jiamusi 154007, China \\ achensiyuybl@163.com;*wtltong@163.com(*Corresponding Author)
}

\begin{abstract}
Based on the analysis of advantages and disadvantages of traditional teaching mode , a teaching reform methods was proposed which used virtual instrument experiment teaching mode to cultivate innovative talents. As an example, "signal and system" course practice was illustrated by the application of virtual instrument in the teaching. The results showed that the introduction of the virtual instrument not only cultivated the students' actual operation ability, and also cultivated their flexibility using textbook knowledge and the ability of design and innovation independently.
\end{abstract}

KEYWORD: LabVIEW; Teaching mode; Innovation ability;

\section{INTRODUCTION}

The cultivation of innovative talents depends on the improvement of practical ability, the domestic and foreign universities have attached great importance to cultivate the students' practical ability. The Chinese ministry pointed out: "Entrepreneurship and innovation education carried out and actively encouraged college students self-employment in colleges and universities were important channels to deepen the reform of the higher education teaching and cultivating students' innovative spirit and practice ability. Traditional teaching mode emphasized on classroom teaching and invested less in the experiment and practice. It led to a lack of personal cultivation and ignored the cultivation of students' innovative ability.

The emergence of virtual instrument is a revolutionary new technology. Virtual Instrument application software integrated all the collection of the instrument such as control, data analysis, result output and functions, user interface .It made some hardware and the traditional instruments replaced by computer software[1]. Many domestic universities have put the virtual instrument technology applied to teaching process[2-4]. In the teaching process, students can make their own designs to exercise their independent conception ability and design according to the experiment requirement to stimulate students' interest in learning.

Based on the analysis of advantages and disadvantages of traditional teaching mode, a teaching reform methods was proposed which used virtual instrument experiment teaching mode to cultivate innovative talents. It provided a reliable basis for the reform of the teaching mode.

\section{TRADITIONAL TEACHING MODE}

\subsection{Traditional teaching mode}

Traditional teaching mode emphasized on classroom teaching and invested less in the experiment and practice. And experiment projects in colleges and universities have many verification experiments lacking innovation and experiment content in colleges and universities. The cultivation of the engineering talents should pay more attention to students' perceptual knowledge in knowledge, stimulate their creation inspiration and improve the innovative ability of students.

\subsection{Traditional experimental facilities and resources}

The labs of colleges and universities adopted mostly the traditional instrument and equipment, the instrument function were poor universality. Traditional experimental equipment were fixed by the intrinsic hardware. Only specific experimental projects and experimental operation added new functions to be updated hardware or buy a new experimental equipment and the investment was bigger. At present, in many colleges and universities haven't enough money to buy a large number of experimental equipment, the existing number of 
experimental equipment couldn't match with the number of students in expanding. Although the traditional teaching mode can satisfy the basic teaching requirements and conform to the laws of theory to guide practice, but the traditional teaching mode has a lack of personal cultivation leading to attach great importance to theory and ignore the cultivation of students' innovative ability.

Therefore, the innovative talent training mode reform is imperative in the severe case of traditional training pattern behind the employment situation and competition increasingly severe.

\section{BASED ON VIRTUAL TEACHING ENVIRONMENT OF TEACHING REFORM}

\subsection{Set up virtual network laboratory}

The development of Virtual Instrument technology is targeted to open design providing the technical support for comprehensive and apply experiment content.

At present, a lot of schools have set up the network virtual instrument laboratory through the use of virtual instrument software development and web publishing function in combination with other technologies to form a virtual laboratory. Such as Beijing University of Posts and Telecommunications, China Petroleum University, Shantou University, Northern University for Nationalities, and so on. The research center of Beijing University of Posts and Telecommunications network teaching system is one of the domestic earlier in network open virtual experiment teaching research institutions.

They have very good application of information technology to the teaching management improving the efficiency of teaching and learning. They had built up the integrated management of open laboratory system, an open online virtual laboratory and course series, computer network skill training system and so on to improve the students' practical ability and innovative ability [5].

\subsection{The application of Virtual Instrument in class experiment}

Virtual instrument technology was applied to teaching, not only can make students more comprehensive to understand and master the basic knowledge and improve the students' practical and innovative ability but also can extend the students' knowledge.

Zhu Aihua (Tianjin University) built virtual signal experimental platform in view of the signal convolution process and sampling theorem by using the LabVIEW software[6]. Liu yan (Yancheng Teachers College) analyzed the advantages and disadvantages of the virtual experiment platform based on MATLAB and based on LabVIEW。 She developed automatic control principle virtual experiment system on the front of panel designed by using LabVIEW corresponding to the rear panel program by using the Actvie $X$ technology and MATLAB programming. Practice showed that it fully aroused the enthusiasm of the students and improved the teaching quality[7]. Zou Da-peng (Guangdong Industry University) aimed at training students the ability of design and developing a computer aided testing system. In the teaching process of testing technology, proportional valve test system was established combining virtual instrument and the teaching contents. It provided the argumentation and instance for teaching reform [8].

\section{INNOVATION ABILITY TRAINING BASED ON VIRTUAL INSTRUMENT EXPERIMENTAL TEACHING MODE}

\subsection{Pay attention to interdisciplinary, increased the proportion of elective courses}

Many universities pay attention to interdisciplinary construction abroad. For example, Stanford university demand to study the introduction to the humanities for a year. Students of Harvard University must choose a core course in other areas [9]. Appropriately increasing the proportion of elective courses, combining with a crossdisciplinary, enriching the content of courses, optimizing knowledge structure of students are all very important.

Teachers should make full use of the virtual instrument and other advanced teaching methods and make the teaching content more vivid, intuitive. It can be mastered easily by student and cultivate their innovative consciousness.

\subsection{The gradually improvement of the existing teaching pattern, inspiring students' innovation consciousness}

Improving existing experiment model by means of the experiment box, all kinds of information technology should be fused to the teaching process.

Using the related virtual instrument gave full play to the students' creative thinking. The same theory can use different experimental methods to test and verify inspiring the student to look at things from different angles. Pay attention to design before class and discussion after class. It can make for the teachers and students think, practice and innovation, and improve students' scientific research ability.

\subsection{To adjust the practice teaching link}

Practice teaching system should be built including experimental skills training, engineering practice 
training, social practice and training.

Engineering application and innovation ability were cultivated to improve the overall quality on the basis of the core competencies required for professional ability. Students should participate all kinds of scientific and technological innovation, science and technology competition in the school, provincial and enterprise. Students can make full use of the practice base and innovation lab.

It formed Multi-level practical teaching system including comprehensive engineering practice, innovation of science and technology, science and technology competition, professional skills training and participation in the teachers' scientific research project.

\subsection{The assessment mode diversification}

To cultivate innovative talents as the goal, the assessment mode diversification was a good way to encourage and motivate self-confidence. Due to a variety of new teaching methods such as virtual instrument, students can flexible design scheme according to their own experiment content. Checking knowledge by the single examination paper has not shown their comprehensive performance grasping theoretical knowledge and relevant skills. The final assessment methods should change the single examination paper using the kinds of combined examination way. The mastery of knowledge and skill level were evaluated by aspects including basic theory, innovation ability, skills, team cooperation.

\section{TEACHING PRACTICE BASED ON THE VIRTUAL INSTRUMENT}

LabVIEW is a graphical language using icon instead of textual lines which used to establish the test, measurement and automation applications of. Unlike text-based programming language, LabVIEW programming using data flow, data flow decision execution. Compared with other simulation software, the LabVIEW powerful combined with hardware and even "implant" hardware feature makes it easier on hardware implementation. It was also more likely to institute design algorithm and the correct line, effectiveness and applicability of the system[10].The flexibility of LabVIEW, die never change and its the convenience of programming made students learn and master conveniently.

Based on the curriculum practices of "signals and systems" as an example, this paper analyzed the virtual instrument in the application of the students' innovative ability training."Signals and systems" is the engineering professional compulsory foundation courses. The main teaching content included signal filtering and sampling, truncation, modulation and demodulation, the waveform analysis of signal time domain, the frequency spectrum analysis of frequency domain signal and the analysis of power spectrum and etc.

In the process of classroom teaching, the use of virtual instrument could be appropriate to join the combination of theory and practice to get better teaching effect. The main goal of the course practice was to use the LabVIEW realizing the temperature and humidity data acquisition in the upper machine. Data sampling module utilized the single chip microcomputer to realize the temperature and humidity real-time acquisition, the circuit state signal acquisition and data preprocessing. The data transmission module could detect signal and transfer to the computer and upload data on the LABVIEW platform through the I/O port. The students realized the real-time acquisition and monitoring of temperature and humidity using LABVIEW program edited. At the same time, it can display the real-time output curves of temperature and humidity on the front panel. Students showed a great interest in learning in the process of the practice. They detailed discussed on the choice of components and functions realization.

Everyone designed different schemes in the group and discussed these programs. Each student in the group can optimized his own scheme according to the results of the discussion. As shown in figure 1, students designed LabVIEW programming window and the procedure of temperature and humidity data collecting.
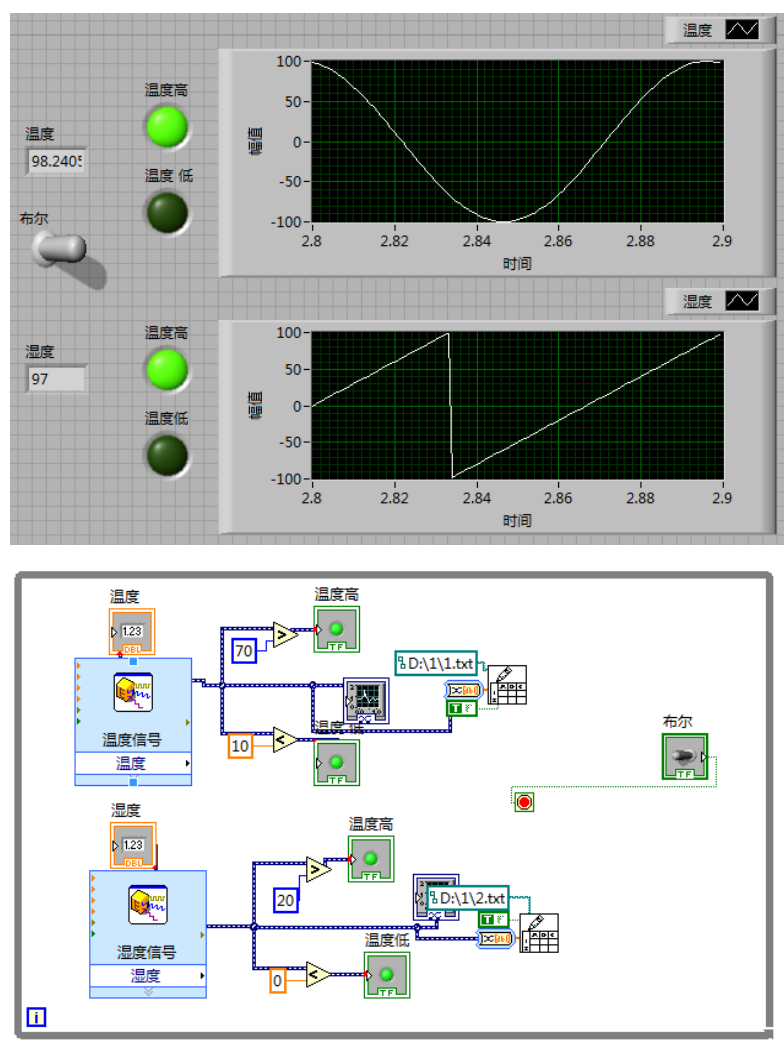

Figure 1 Temperature humidity acquisition window and LabVIEW program 


\section{CONCLUSION}

Practice showed that the application of virtual instrument in teaching mode not only strengthened the different disciplines and curriculum theory but also improved the students' comprehensive ability, innovation ability and the team cooperation spirit. It can give full play to their subjective initiative, stimulate the learning interest of students and increase the efficiency of experimental equipment. The introduction of virtual instrument not only cultivated the practical ability of student but also cultivated their flexibility in the use of textbook knowledge, connection between theory and practice and the ability of independent design and innovation.

Through the use of virtual instrument, student grasped a new way to learn new knowledge and had a comprehensive test of the knowledge and review.

\section{ACKNOWLEDGEMENTS}

This work was supported by Higher Education Scientific Research Projects of Heilongjiang Province (14G135, 14Z023); Jiamusi University Teaching Research Projects (JYLB2013-01, JYLA2012-007); Jiamusi University Science Research Project (Lzp2012-03) and Jiamusi University Science and Technology Innovation Team Building Program (Cxtd-2013-01).

\section{REFERENCES}

[1] Liu Junhua,etc. The virtual instrument graphical programming language LabVIEW course. $\mathrm{Xi}$ 'an: $\mathrm{Xi}$ 'an University of Electronic Science and Technology Press, 2001.

[2] Cao Jianrong, etc. The Virtual Instrument technology in the application of the principle of automatic control experiment. Laboratory Research and Exploration, 2004, 3 (5):38-40.

[3] Luo Kaiyu, etc. The strain test system based on the Virtual Instrument technology. Jour nal of Jiangsu University (natural science edi tion), 2005(2):106-109.

[4] Gu JuChun, etc. The virtual experiment platform design of automatic control theory course. Colleges and Universities Laboratory Research 2008(1):50 to 52.

[5] Zhang Qiong,etc. The research center of Beijing University of Posts and Telecommunications network teaching system, irtual simulation research and innovation of experimental teaching trait and industry science and technology, 2014, (7): 78-80.

[6] Zhu Aihua, etc. Virtual signal experiment platform based on LabVIEW. Experimental Technology and Management, 2005, 22 (4): 70-72.

[7] Liu yan. "automatic control principle" experimental teaching reform explore based on the Virtual Instrument, Forest Teaching, 2009, (11) : 9-10.

[8] Zou Dapeng, etc. Testing technology teaching reform research based on the Virtual Instrument technology to realize journal of guangdong university of technology (social science edition), 2007, 7 (suppl) : 104-107.

[9] Porter, Alan L. A systems model of innovation processes in university STEM education. Journal of Engineering Education, January, 2006, 5(1):78-82.

[10] Yang Zhi. Virtual Instrument Teaching Experiment Introductory Tutorial. Beijing University of Aeronautics and Astronautics press, 2008. 